\title{
DISCLAIMER
}

This repont wat prepared as an acoount of work spononod by an ageacy of the United States Government. Neither the Unitod States Government sor any aceacy thereor, nor ay of their

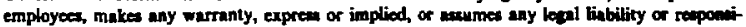
bility for the accuracy, comptesences, or usefulaces of any information, appantus, probet, or process disclowed, or represents that its use would not infringe privately owned rigitul Refer-

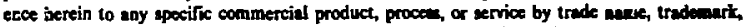
manufacturer, or otherwice does not necenarily constitute or ingly its endorsement, reconmendation, or favoring by the United State Gorernmeat of any apency thereof. The riom and opiniont of authors exprested herein du not nocestarily stale or refloct thowe of the Uaited Sules Government or any ugency thereor.

\section{Protecting Against Failure by Brittle Fracture in Ferritic-Steel Shipping Containers Greater Than Four-In. Thick

\author{
M. W. Schwartz
}

Manuscript date: December, 1982

\author{
Prepared for: Mechanical/Structural Engineering Branch \\ Dvision of Engineering Technology \\ Office of Nuclear Reg. Res. \\ Washington, D.C. 20852
}

\section{LAWRENCE LIVERMORE LABORATORY University of California • Livermore, California • 94550}


This report summarizes the results of research conducted to develop fracture-toughness acceptance criteria for spent fuel shipping containers made from thick-wa!l ferritic steel forgings. The work was done by Lawrence Livermore National Laboratory and was funded by the Mechanical/Structural Engineering branch within the Division of Engineering Technology of the Nuclear Regulatory Commission. This report contains no specific recommendations since it is anticipated that such recommendations will be supplied in conjunction with a follow-up value impact evaluation.

The author wishes to thank Eugene Lange of the Naval Research Laboratory, Washington, D.C., (retired) for his assistance in developing the approaches set forth in this report, and Professors S. T. Rolfe and H. T. Corten for their valuable comments on the preliminary draft. 
Preface.............................................. ii

List of Illustrations.................................... iv List of Tables............................................ v

Nomenc lature............................................ vi

Executive Summary......................................... vii

Abstract............................................ 1

1. Introduction. ........................................ 2

1.1 objectives of the Research............................ 2

1.2 Background........................................ 2

1.3 Approach $\ldots \ldots \ldots \ldots \ldots \ldots \ldots \ldots \ldots \ldots \ldots \ldots \ldots \ldots \ldots \ldots \ldots \ldots \ldots \ldots \ldots \ldots \ldots, \ldots$

2. Methodology $\ldots \ldots \ldots \ldots \ldots \ldots \ldots \ldots \ldots \ldots \ldots \ldots \ldots \ldots \ldots \ldots \ldots \ldots \ldots \ldots \ldots \ldots \ldots \ldots .6$

2.1 Prevention of Brittle Fracture Based on FractureArrest Principle................................... 6

2.2 Prevention of Brittle Fracture Based on EractureInitiation Principle................................ 14

2.3 Acceptance Criterion Based on Testing.................... 26

3. Sensitivity of Ferritic Steel Shipping Containers to

Fabrication Processes...................................... 31

3.1 Fabrication of Forging Billete....................... 31

3.2 The Forging Process............................... 31

3.3 Heat Treatment.................................... 32

3.4 Welding....................................... 33

References............................................ 35

Glossary............................................ 37

Appendix A: Critical Through Crack Size......................... 38

Appendix B: Thick Section $\mathrm{K}_{\mathrm{ID}} / \sigma_{\mathrm{YD}}$ Design Reference Curve............ 40 
Figure 1. Design Chart for Category I Fracture Critical Components

Up to $4 \mathrm{In}$. Thick.............................. 3

Figure 2. Design Reference $K_{I D}$ Curve...................... 5

Figure 3. Construction of Fracture Arrest Curve................. 7

Figure 4. Method of Determining $(L)$ and $(Y C)$ Coordinates............ 8

Figure 5. Exponential Fracture Toughness Reference Curve............. 10

Figure 6. Fracture Arrest Boundary Curves for a Range of Wall Thicknesses Based Upon Extrapolated Exponential Fracture Toughness keference Curve......................... 12

Figure 7. Static and Dynamic Toughness Curve for Ferritic Steels........ 13

Figure 8. Relationship of Fracture Toughness and DT Energy to Temperature................................... 15

Figure 9. Projected Fracture Toughness Reference Curve................ 16

Figure 10. Method of Establishing (YC) Coordinates for a Range of Wall Thicknesses.................................. 17

Figure 11. Method of Establishing (L) Coordinates For a Range of Wall Thicknesses.................................. 18

Figure 12. Fracture Arrest Boundary Curves for a Range of Wall Thicknesses..................................... 19

Figure 13. Membrane Stress Correction Factor for Surface Flaws.......... 21

Figure 14. Crack-Shape Parameter Curves......................... 22

Figure 15. Fracture Toughness Level Corresponding to Critical Flaw Depth for Surface Flaw with Aspect Ratio of 0.5 for all thickness...................................... 23

Figure 16. Fracture Toughness Level Corresponding To Critical Flaw Depth for Surface Flaw with Aspect Ratio of $1 / 6 \ldots \ldots \ldots \ldots \ldots \ldots .24$

Figure 17. Fracture Toughness Level Corresponding to Critical Flaw Depth for Surface Flaw With Aspect Ratio Approaching Zero......

Figure 18. Table from ASTM Section XI Specifying Minimum Tolerable Flaw Sizes as a Function of Section Thickness and Flaw Aspect Ratio................................... 27

Figure 19. NIL Ductility Transition Temperature Requirements for Thick Wall Forgings Based Upon Fracture Initiation Criterion......... 
Table 1. $\mathrm{T}_{\mathrm{NDT}}$ requirements for $\mathrm{LST}=-20^{\circ} \mathrm{F}$ using exponential $\mathrm{K}_{\mathrm{ID}} / \mathrm{a}_{\mathrm{YD}}$ reference curve (based on Pellini data)................... 12

Table 2. $\mathrm{T}_{\mathrm{NDT}}$ requirements for: $\mathrm{LST}=-20^{\circ} \mathrm{F}$ using asymptotic $\mathrm{K}_{\mathrm{ID}} / \mathrm{a}_{\mathrm{YD}}$ reference curve....................................... 19

Table 3. T TDT requirements based upon minimum ASME Section XI flaw sizes for brittle fracture using the fracture iniziation approach $. . \ldots \ldots \ldots \ldots \ldots \ldots \ldots \ldots \ldots \ldots \ldots \ldots \ldots \ldots \ldots \ldots \ldots, 28$ 


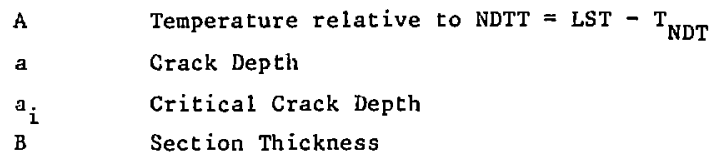

A Dimensionless Parameter, $\frac{1}{B}\left(\frac{K_{I D}}{\sigma_{Y D}}\right)^{2}$

$\mathrm{K}_{\mathrm{I}}$

Stress Intensity Factor

Critical Value of $K$, for Static Loading Rates

Critical value of $K$, for Dynamic Loading Rates

Crack Length

Lowest Service Temperature

Limit for Brittle Fracture under Plane Strain Conditions

Factor that Reflects Flaw-Depth-to-Thickness Ratio

Nil Ductility Transition Temperature

Ratio of Through Crack Length to Section Thickness

Flaw Shape Factor

Nominal Stress

Yield Strength for Static Loading Rate

Yield Strength for Dynamic Loading Rate

$$
\begin{aligned}
& =\sigma_{Y S}+30 \mathrm{ksi} \text { for Steel with } \sigma_{Y S} \leq 60 \mathrm{ksi} \\
& =\sigma_{Y S}+15 \mathrm{ksi} \text { for steel with } \sigma_{Y S} \geq 70 \mathrm{ksi} \\
& =\sigma_{Y S}+20 \mathrm{ksi} \text { for steel with } 60 \mathrm{ksi}<\sigma_{Y S}<70 \mathrm{ksi}
\end{aligned}
$$

Required Nil Ductility Transition Temperat.ure

Yield Criterion; the level of toughness required to provide fracture arrest at a nominal stress equal to the yield strength. 


\section{EXECUTIVE SUMMARY}

The purpose of this study was to develop criteria that will prevent brittle fracture of shipping containers made of thick-wall ferritic steel forgings under hypothetical accident conditions which result in high levels of dynamic loading. The procedures used were based upon the principles of linear elastic fracture mechanics which underpin the fracture arrest and fracture initiation approaches. In the former, prevention of brittle fracture is assured by selecting steels having Nil Ductility Transition Temperatures (NDTT) low enough to guarantee arrest of through-thickness cracks at the lowest service temperature and dynamic yield stress loading. The latter requires materials of sufficient toughness to prevent initiation of brittle fracture in the presence of a flaw of specified size and a maximum allowable stress in the vicinity of the flaw. The fracture arrest approach involves establishing an idealized crack arrest boundary similar to that of the classical fracture analysis diagram for a particular thickness under consideration. This requires a relationship between fracture toughness critical stress intensity and temperature. Such a relationship was provided by Pellini for a temperature up to NDTT $+110^{\circ} \mathrm{F}$ which is satisfactory for evaluating thicknesses up to $4 \mathrm{in.} \mathrm{thick.} \mathrm{For} \mathrm{thicknesses} \mathrm{greater} \mathrm{than} 4$ in., it was necessary to extrapolate this curve. The rule for extrapolating the toughness/temperature relationship was based on the recognition that a limiting transition temperature range exists beyond which plane strain constraint is no longer possible regardless of the thickness of the material. Even so, the NDTT requirement for the material ranged from $-123^{\circ} \mathrm{F}$ to $-146^{\circ} \mathrm{F}$ for thicknesses of $4 \mathrm{in.} \mathrm{and} 20 \mathrm{in.} \mathrm{respectively} \mathrm{at} \mathrm{yield} \mathrm{stress} \mathrm{levels,} \mathrm{and}$ from $-90^{\circ} \mathrm{F}$ to $-135^{\circ} \mathrm{F}$ at $20 \%$ of yield stress levels. Since it would be difficult to obtain ferritic steel forgings of the required thickness in this NDTr range the fracture initiation criteria was also investigated. The NDTT requirement for the ferritic steel forgings using this approach were based upon limiting flaw sizes to one-half the critical size as recommended by ASME Section XI and assuming yield levels of stress. For the most conservative assumptions of flaw shape and orientation the NDTT requirements were $-65^{\circ} \mathrm{F}$ to $-120^{\circ} \mathrm{F}$ for thicknesses of $4 \mathrm{in}$. and $20 \mathrm{in}$. respectively at yield stress levels. 
The brittle-fracture sensitivity of shipping containers fabricated from ferritic steel forgings was investigated from the standpoint of toughness level, flaw introduction and residual stress. The processes which can affect tisese fracture-resistance parameters are

- the fabrication of the forging billet, which can introduce various kinds of imperfections

- the forging process including heat treatment, which has a significant effect on fracture toughness levels

- welding, which not only affects the level of toughness but introduces various defects and residual stresses. 


\author{
Protecting Against Failure \\ by Erittle Fracture in \\ Ferritic-steel Shipping \\ Containers Greater Than \\ Four In. Thick
}

\section{ABSTRACT}

This report presents methods for protecting against brittle fracture spent-fuel shipping containers made from ferritic-steel forgings greater than four in. thick. Both fracture arrest and fracture initiation criteria were examined as bases for establishing requirements for the design and selection of materials for shipping containers. This report also includes a discussion of the brittle-fracture sensitivity of the containers to various processes used in container fabrication. 


\section{INTRODUCTION}

\subsection{OBJECTIVE}

The objective of this study was to develop generic fracture-toughness acceptance criteria for thick-wall ferritic steel forgings that may be used for fabricating reactor spent-fuel shipping containers. This objective includes consideration of methods for demonstrating that these acceptance criteria are satisfied. A further objective is to identify, with regard to fracture resistance, the sensitivity of the material to various production processes, such as wtlding or heat treatment, and to identify the type and size of typical flaws that can be expected in the construction of shipping containers made from ferritic steel forgings.

\subsection{BACKGROUND}

A prior study ${ }^{1}$ has been made by the Lawrence Livermore National Laboratory dealing with recomendations for protecting against brittle fracture in ferritic steel shipping containers up to four in. thick. The approach used was based upon 1 inear-elastic fracture mechanics using a dynamic critical-stress intensity curve referenced to the Nil Ductility Transition Temperature (NDTT) and normalized to the dynamic yield stress at the NDTT. For Category I containers, requiring the highest level of safety, the recommended method for preventing brittle fracture was to select material of such toughness that arrest of cracks penetrating the wall would be assured at the lowes: anticipated service temperature under conditions of dynamic-yield stress loading. A material having this level of toughness would not fail ia a brittle manner even if part-through cracks existed or were subsequently produced at locally enbrittled areas. Consequently, no special iuspection criteria are required to limit initial flaw sizes. While material selection based upon anticipation of yield stress levels is recommended, a relaxation of the material requirements is allowed where it can be demonstrated that stresses lower than yield cannot be exceeded. The recommendations for protecting against brittle fracture of category I shipping containers up to four in. thick are summarized in Fig. $3 \mathrm{or}$ Ref. (1) and are reproduced tiere in Fig. 1 


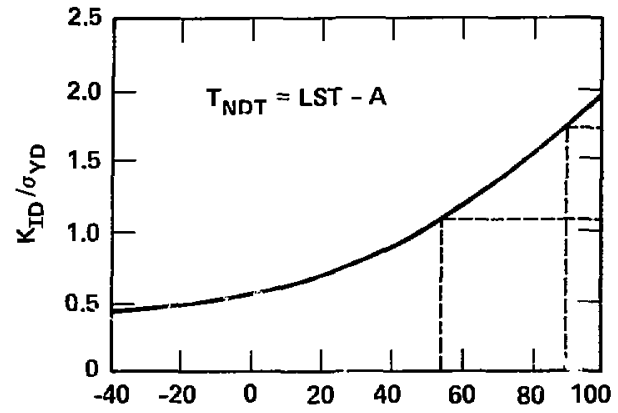

$A\left({ }^{\circ} \mathrm{F}\right)$

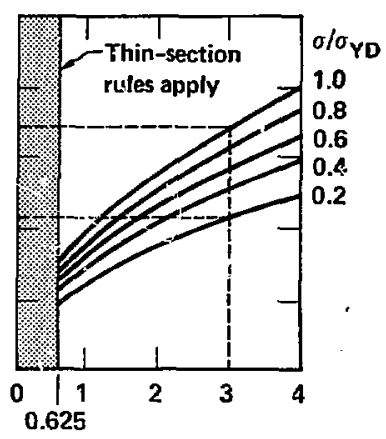

Thickness (in.)

Figure 1. Design Chart for Category I Fracture Critical Components Up to 4 In. Thick (Ref, 1) 
for reference. This figure illustrates the procedure for determining the required Nil Ductility Transition Temperature, $T_{\text {NDT, for a three-in. wall }}$ thickness both at yield stress and at $20 \%$ of the yield stress.

\subsection{APPROACH}

For ferritic steel thicknesses greater than four in., that is, ferritic steel forgings applicable to the construction of thick-wall monolithic casks for Category I service, an appruach based upon linear-elastic fracture tnechanics is also used. Where possible, the methodology for treating thick-wall forgings seeks to be consistent with that applied to thicknesses less than four in. Consequently, to the extent that it is applicable to thick sections, the Pellini-based relation of dynamic critical stress intensity to NDTT, shown in Fig. 2, was used. ${ }^{2}$ In addition, the practice of qualifying steels based upon their NDT cemperature was retained. Furthermore, it was recognized that any relaxation of NDTT requirements would have to be compensated for by control of other fracture-related parameters such as establishing stress or flaw-size limits.

It is not the intent of this study to make specific recommendations with regard to adopting any particular approach but rather to present the results of the investigation as a basis for assessing the impact of the various approaches on the regulatory functions of the NRC and other government agencies, the shipping container industry, and the public. 


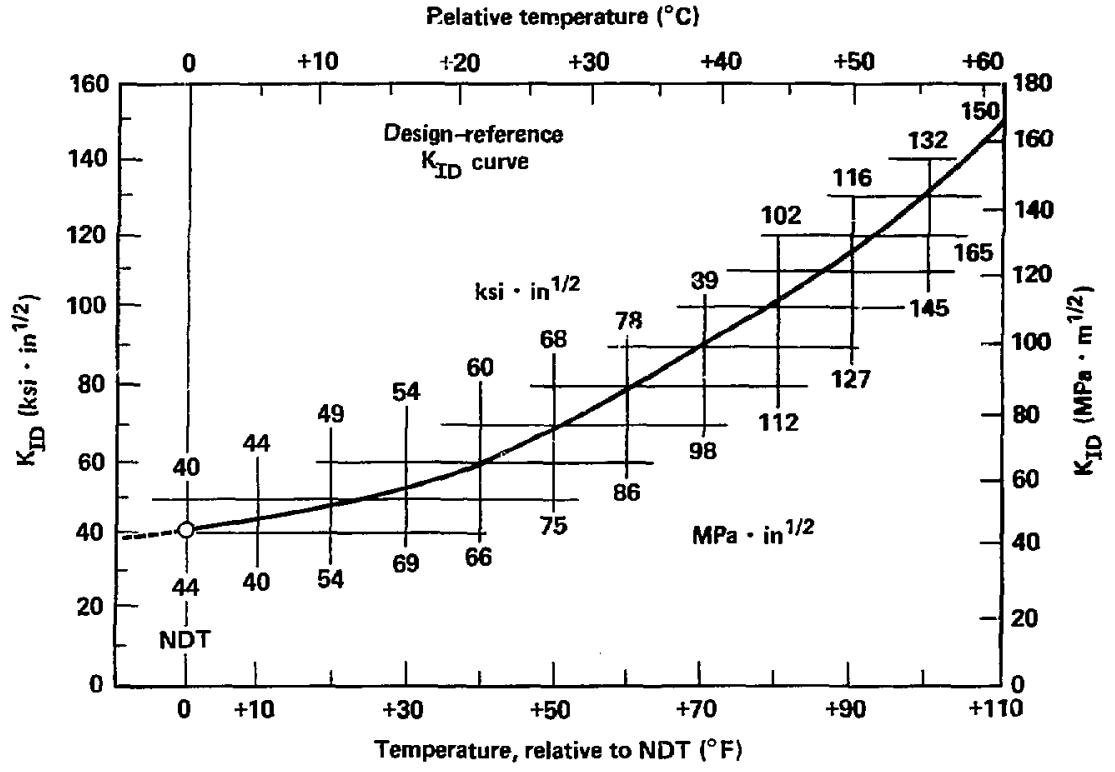

Figure 2. Design Reference $K_{\text {ID }}$ Curve (Ref. 2). 


\section{METHODOLOGY}

Consistent with the Pellini approach to the prevention of brittle fracture as destribed in Ref. 1 , the analysis for thick wall ferritic steel shipping containers recognizes the principles of fracture arrest and fracture initiation as the two bases for developing fracture-control criteria. Invoking the fracture arrest principle as a means of preventing brittle fracture requires that materials be selected of sufficient toughness to preclude extension of a through-wall crack under dynamic yield stress loading irrespective of the crack size. The fracture initiation principle, on tine other hand, precludes crack extension if the combination of stress and flaw size does not result in a stress intensity $\left(K_{I}\right)$ greater than the critical value fracture-toughness stress intensity $\left(K_{I D}\right)$ of the chosen material.

\section{2. $i$ PREVENTION OF BRITTLE FRACTURE BASED ON THE FRACTURE ARREST PRINCIPLE}

The procedure for selecting a ferritic steel having acceptable fractura toughness involves ccnstructing a curve delineating the limits of throughcrack arrest behavior similar to that of the classical fracture-analyses diagram (FAD). In the Pellini approach, this curve is idealized as a straight line defined by end points designated as $L$ and $Y C$ on a coordinate system relating stress states to teference NDTT as shown in Fig. 3. The $L$ point corresponds to the temperature limit for crack extension under plane strain condicions for a particular wall thickness, B, defined by

$$
B=\frac{1}{\beta}\left(\frac{\mathrm{K}_{\mathrm{ID}}}{\sigma_{\mathrm{YD}}}\right)^{2}
$$

where $\beta=0.4, K_{I D}$ is the critical stress intensity and $\sigma_{Y D}$ is the dynamic yield strength of the steel. The fracture toughness ratio, $\mathrm{K}_{\mathrm{ID}} / \sigma_{\mathrm{YD}}$, corresponding to a particular thickness can be found from Eq. (1). The reference NDTT corresponding to this ratio can be determined from $\mathrm{Fig}$. 4 which redefines the toughness/temperature relation of Fig. 2 in cerms of the $\mathrm{K}_{\mathrm{ID}} / \sigma_{\mathrm{YD}}$ ratio. The curve in Fig. 4 is indexed such that at the NDTT the $\mathrm{K}_{\mathrm{ID}} / \sigma_{\mathrm{YD}}$ ratio is equal to the value of 0.6 recommended by 


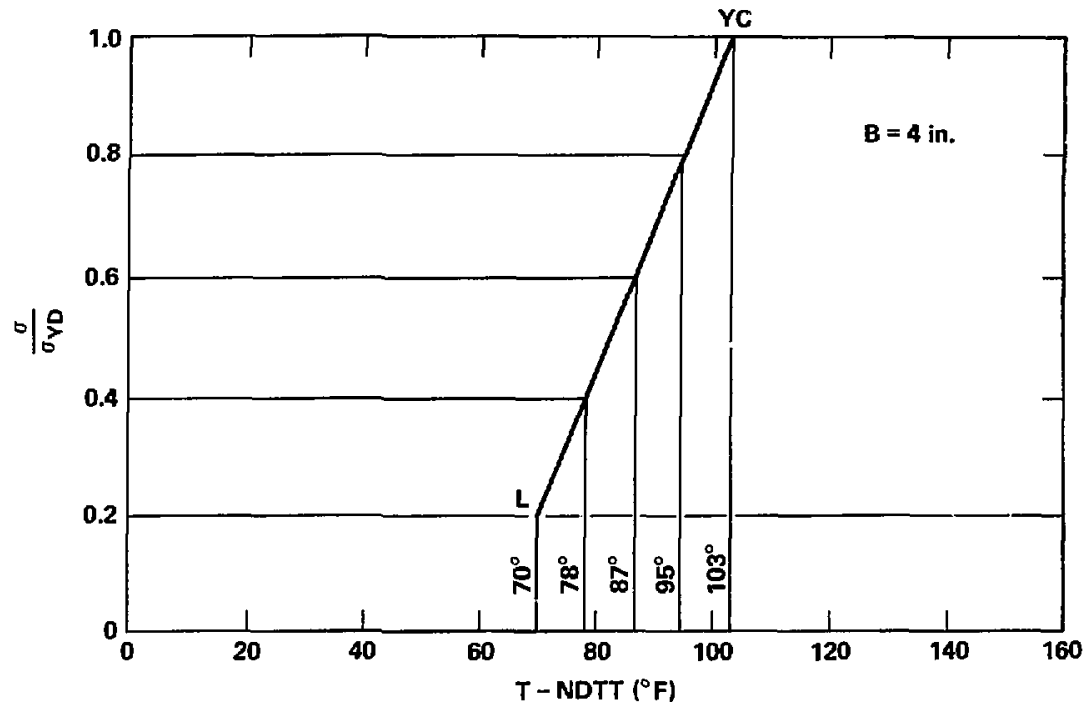

Figure 3. Construction of Fracture-Arrest Curve. 


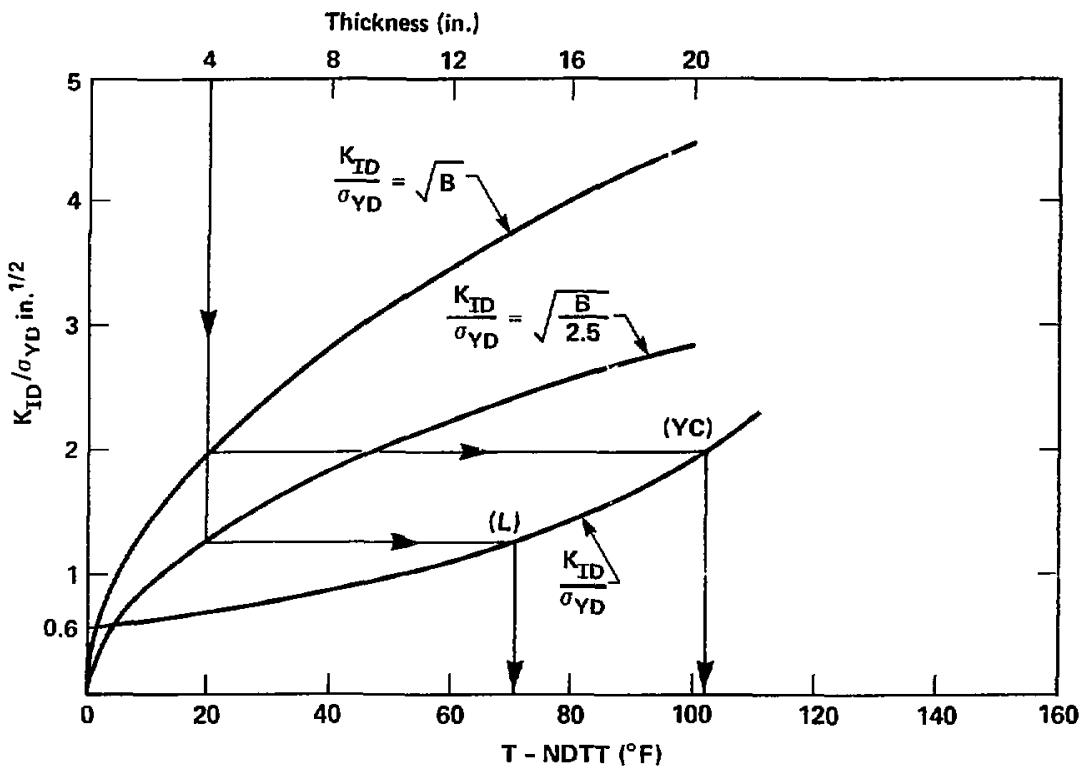

Figure 4. Nethod of Determining (L) and (YC) Coordinates. 
Rolfe and Barsom. ${ }^{3}$ The rationale for this index is based upon a correlation between dynamic fracture toughness and dynamic yield strength revealed by the drop-weight Nil Ductility Transition Test (NDTT). The additional coordinate which locates $L$ is provided by a level of stress below which fracture instability of a through-crack is precluded. This stress is related to the size of the through-crack that can be tolerateo, and this relation is described in Appendix A. Consistent with the procedure for thin wall containers, the stress ratio, $\sigma / \sigma_{y}$, for $L$ was established at 0.2 which corresponds to a critical through-crack length of about 6 times the wall thickness:

The YC point relates to the temperature limit for through-crack extension at yield stress level for combinations of toughness and wall thickness defined by

$$
B=(1)\left(\frac{K_{I D}}{\sigma_{Y D}}\right)^{2}
$$

At temperatures greater than that coresponding to YC, britcle fracture can no longer be j.nitiated at elestic stress levels, regardless of flaw size.

The reference NTDDs corresponding to $L$ and $Y C$ for a four-in. wall thickness are found as shown in Fig. 4. A reference NDTT of $103^{\circ} \mathrm{F}$ and $\sigma / \sigma_{Y D}=1$ are the coordinates for YC in Fig. 3 while the reference NDTT of $70^{\circ} \mathrm{F}$ and $\sigma / \sigma_{Y D}=0.2$ are the coordinates for $L$. Once the crack-arrest boundary defined by $\mathrm{L}$ and $\mathrm{YC}$ are determined, the reference NDTT for any stress level between $\sigma / \sigma_{y}=0.2$ and $\sigma / \sigma_{y}=1$ can be determined.

It is apparent from Fig. 4 that the extension of this methodology to thicknesses greater than four inches requires an extrapolation of the design reference $\mathrm{K}_{I D} / \sigma_{Y D}$ curve to temperature levels that would accomodate these larger thicknesses. One method of extrapolating this curve is to fit it to an exponential function similar to the $\mathrm{X}_{\mathrm{IR}}$ curve in Appendix $G$ of Section III of the ASME Code. Using the data given by Fig. 2, and assuming a dynamic yield strength of $70 \mathrm{ksi}$, we obtain

$$
\frac{K_{\text {LI }}}{\sigma_{\mathrm{YD}}}-0.39=0.2 \exp [0.02(\mathrm{~T}-\mathrm{NDTT})]
$$


B (in.)

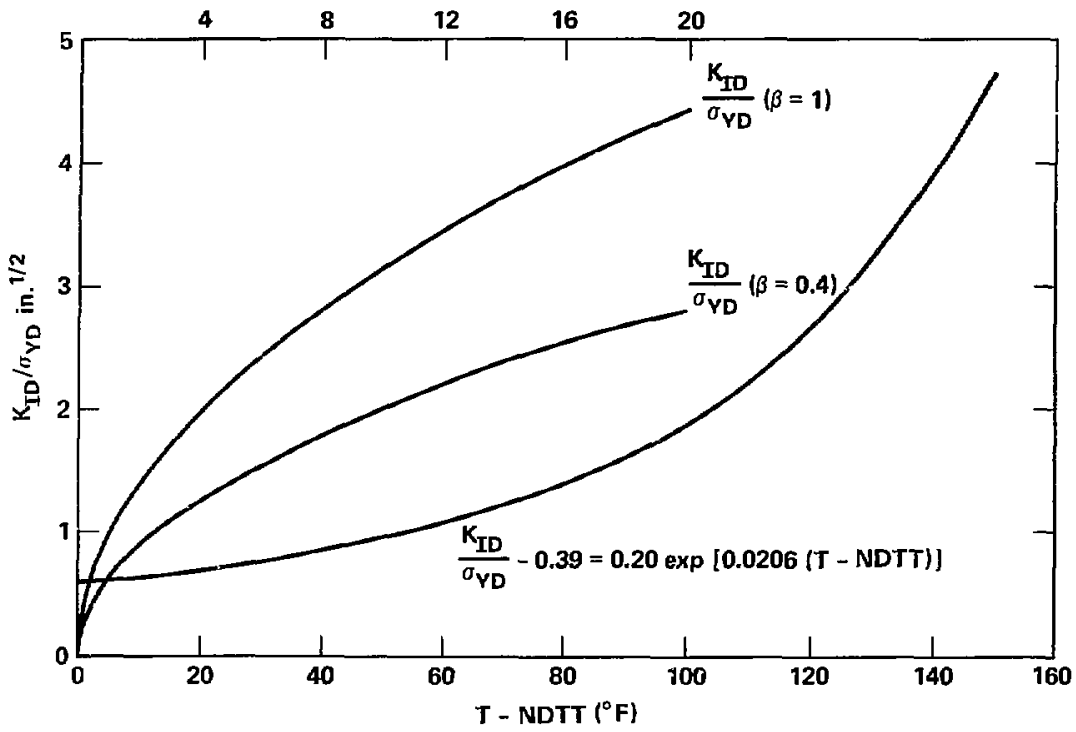

Figure 5, Exponential Fracture-Toughness Reference Curve. 
The exponential fracture toughness curve is plotted in Fig. 5 up to NDTT $+150^{\circ} \mathrm{F}$. Superimposed on this figure are curves relating fracture toughness to thickness for both $L$ and $Y C$ constraint criteria. We can now determine the NDTT requirements associated with $\mathrm{L}$ aid $\mathrm{YC}$ for a range of thicknesses that would envelope any conceivable shipping container thickness requirements. The fracture-arrest boundaries corresponding to this range of thicknesses are shown in Fig. 6, from which we can obtain the required reference NDTTs for various stress levels. Assuming that the lowest service temperature is $-20^{\circ} \mathrm{F}$, the required NDTTs for the ferritic steel are 1 isted in Table 1 for a range of stresses and thicknesses. It should be pointed out that these NDTT requirements need only appiy to the base metal. For the fracture-arrest approach, localized areas of lower toughness do not significantly compromise protection against catastrophic brittle fracture.

While it was possible to extrapolate the Pellini curve by means of an exponential curve $f i t$, there is reason to believe that this assumption is very conservative $^{4}$ for the purpose of selecting steel for thick-wall shipping containers based upon their NDTTs. The design reference $\mathrm{K}_{\text {ID }}$ curve was intended to provide conservative values of $\mathrm{K}_{\mathrm{ID}}$ as a function of temperature that can serve as failure criteria for levels of $\mathrm{K}_{I}$, obtained by Linear Elastic Fracture Mechanics (LEFM) computations. Thus there is an implied assumption that the reference $K_{I D}$ 's reflect plane strain values. For temperatures less than the NDTT, this assumption is correct for through-cracks and edge cracks for wall thicknesses that meet the criterion of Eq. (1). At temperatures greater than the NDTT, plane strain conditions are more difficult to maintain because of the larger crack tip plasticity effects and, with rising temperature, there is an increasing tendency for slow crack growth to occur before the onset of crack instability. Consequently, as the temperature increases, the design reference $K_{I D}$ curve reflects an increasing measure of conservatism in the analysis for unstable crack growth. In fact, there is evidence of a limiting temperature beyond which plane strain conditions cannot be maintained regardless of the thickness of the material. ${ }^{5,6}$ This is illustrated in Fig. 7 for various steels including, A533-B. The figure shows the fracture-toughness values rising steeply past the NDTT and approaching an asymptote which corresponds to a temperature at which large plastic zones form at dynamic loading rates, and which constitute an upper bound for plane strain 


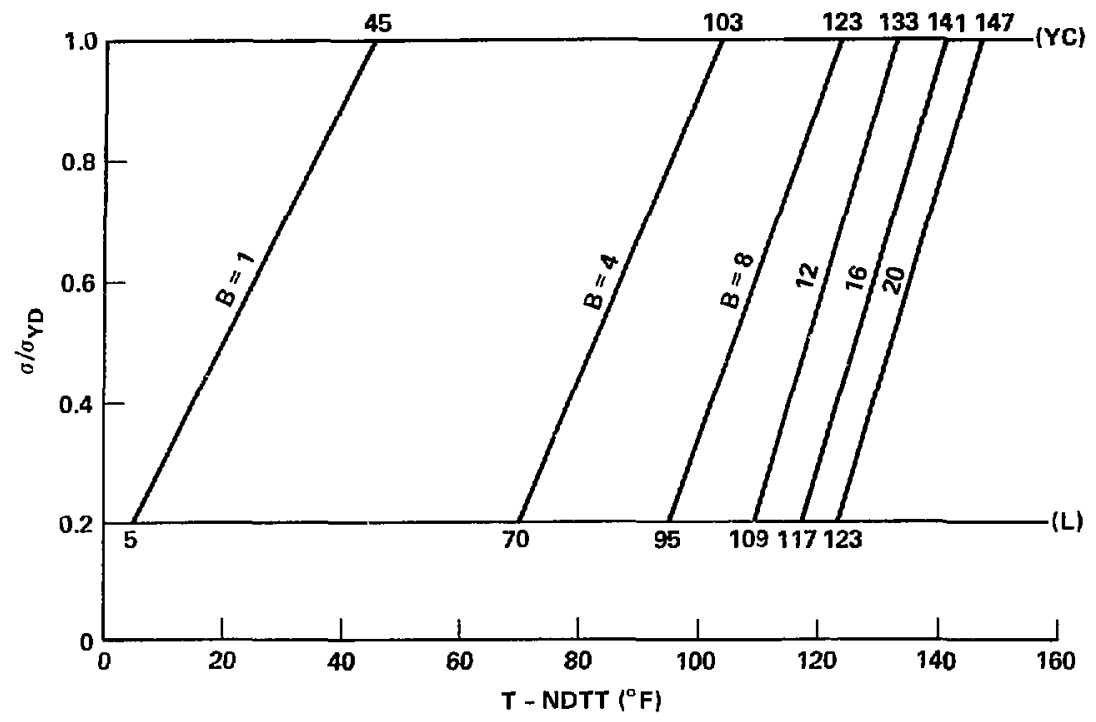

Figure 6. Fracture Arrest Boundary Curves for a Range of Wall Thickness Based Upon Extrapolated Exponential Fracture-Toughness Reference Curve.

Table 1. $\mathrm{T}_{\text {NDT }}$ requirements for LST $=-\angle 0^{\circ} \mathrm{F}$ using exponential $\mathrm{K}_{I D} / \sigma_{\mathrm{YD}}$ reference curve (based on Pellini data).

$$
\mathrm{T}_{\mathrm{NDT}}\left({ }^{\circ} \mathrm{F}\right)
$$

\begin{tabular}{cccccc}
$\begin{array}{c}\text { Thickness } \\
\text { (in.) }\end{array}$ & $\frac{\sigma}{\sigma_{y}}=1.0$ & $\frac{\sigma}{\sigma_{y}}=0.8$ & $\frac{\sigma}{\sigma_{y}}=0.0$ & $\frac{\sigma}{\sigma_{y}}=0.4$ & $\frac{\sigma}{\sigma_{y}}=0.2$ \\
\hline 1 & -65 & -55 & -45 & -35 & -25 \\
4 & -123 & -115 & -107 & -98 & -90 \\
12 & -143 & -136 & -129 & -122 & -115 \\
16 & -153 & -147 & -141 & -135 & -129 \\
20 & -161 & -155 & -149 & -143 & -137 \\
\hline
\end{tabular}




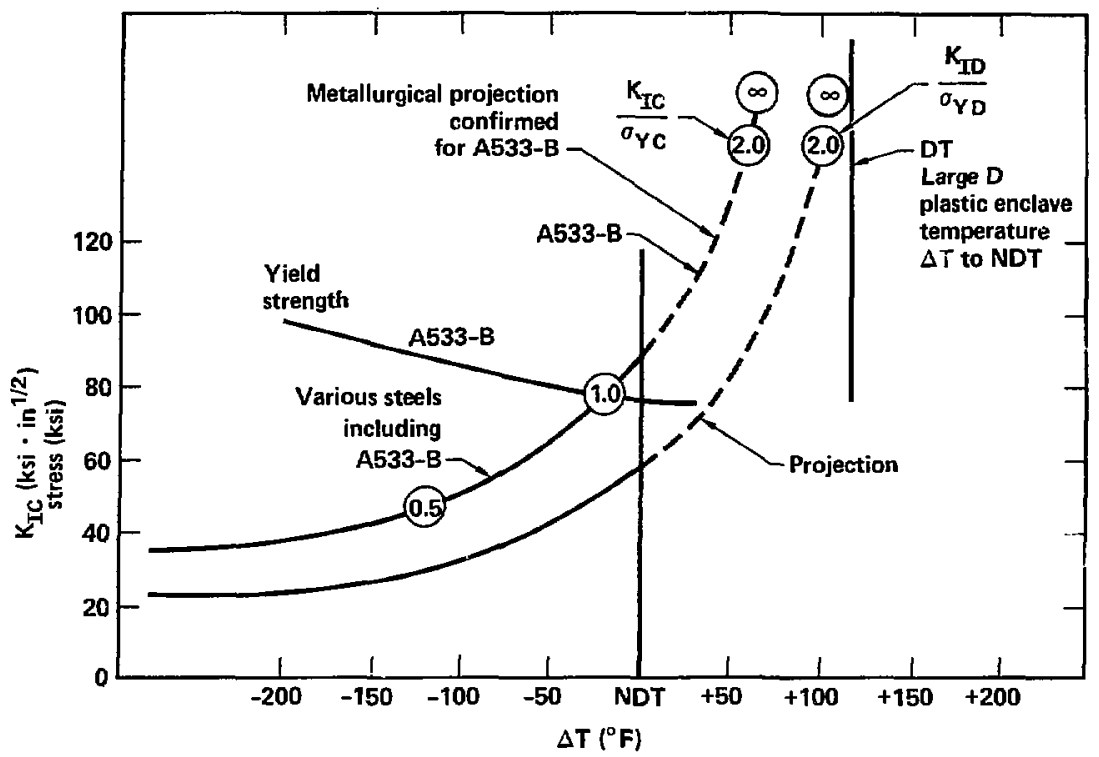

Figure 7. Static and Dynamic Toughness Curve for Ferritic Steels (Ref. 5). 
behavior. It appears, then, that beyond a T-NDTT of $100^{\circ} \mathrm{F}$, the design reference curve should rise more steeply than would be described by an exponential function. One method for establishing the bounding temperature is provided by the dynamic tear (DT) test, which measures fracture toughness under dynamic conditions in terms of the energy required for fracture of a pre-cracked test specimen. The relationship of DT energy to classical fracture toughness properties is illustrated in Fig. 8, which would place the limiting temperature at about $150^{\circ} \mathrm{F}$, or since an NDTT of $10^{\circ} \mathrm{F}$ is indicated, at about NDTT $+140^{\circ} \mathrm{F}$.

The significance of this is that the NDTI requirenents for ferritic steel shipping containers need not decrease without 1 imit as section thicknesses increase. Consequently, a $K_{I D}$ design reference curve is proposed wherein the $\mathrm{K}_{\mathrm{ID}} / \sigma_{\mathrm{YD}}$ ratio for $(\mathrm{T}-\mathrm{NDTT})>100^{\circ} \mathrm{F}$ is an inverse function with $(\mathrm{T}-\mathrm{NDTT})=140^{\circ} \mathrm{F}$ as its asymptote. For $(\mathrm{T}-\mathrm{NDTT})<100^{\circ} \mathrm{F}$ the exponential relationship is maintained. The proposed curve is shown in Fig. 9 based upon the derivation given in Appendix $B$.

Based on the curve shown in Fig. 9 a more realistic set of crack arrest boundary curves may be constructed by defining the temperatures corresponding to $\mathrm{L}$ and $\mathrm{YC}$ as shown in Figs. 10 and 11 , respectively, and placing these p. ints at the appropriate stress level, as shown in Fig. 12. The T NDT requirements for a lowest service temperature (LST) of $-20^{\circ} \mathrm{F}$ are summarized in Table 2 for a range of thicknesses and stress ratios.

\subsection{PREVENTION OF BRITTLE FRACTURE BASED ON THE FRACTURE-INITIATION PRINCIPLE}

Whereas the fracture arrest principle admits the possibility that small cracks in embrittled areas or high-stress regions may extend or initiate, the prevention of brittle fracture by the use of the fracture initiation principle seeks to limit stress levels and pre-existing flaw sizes such that initiation is precluded. The approach requires a high level of assurance that design stress ievels will not be exceeded, and that efficient inspection techniques will be used that will assure the abser -e of flaws larger than the size that would be critical for the chosen material. Since stress analyses may not accurately predict dynamic stress levels or stresses due to discontinuities and those introduced by fabrication processes, it would seem prudent to base 


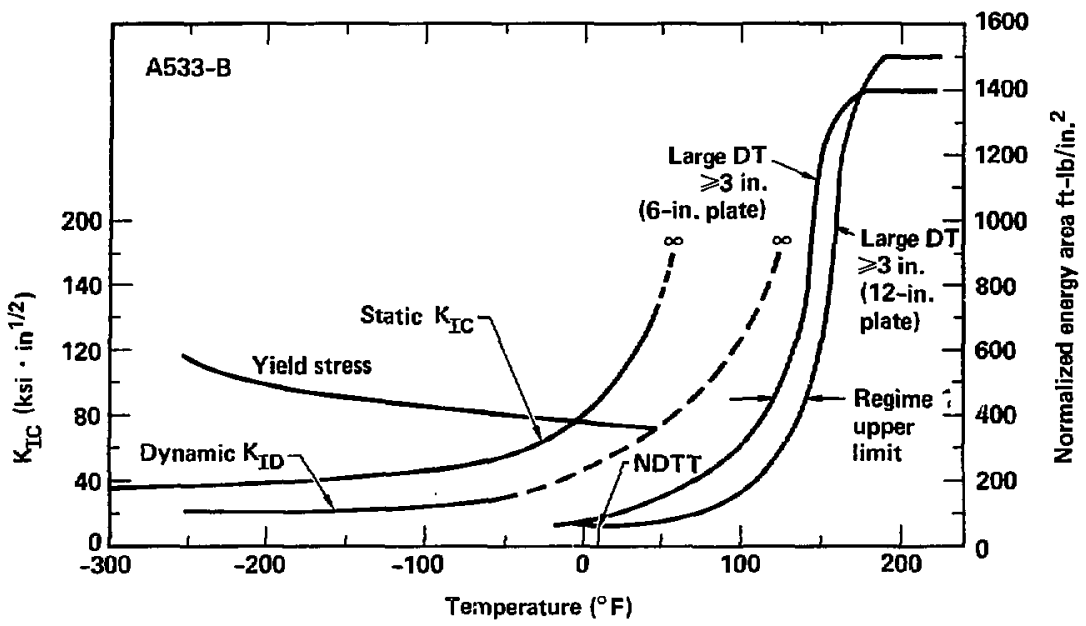

Figure 8. Relationship of Fracture Toughness and DT Energy to Temperature (Ref. 5). 


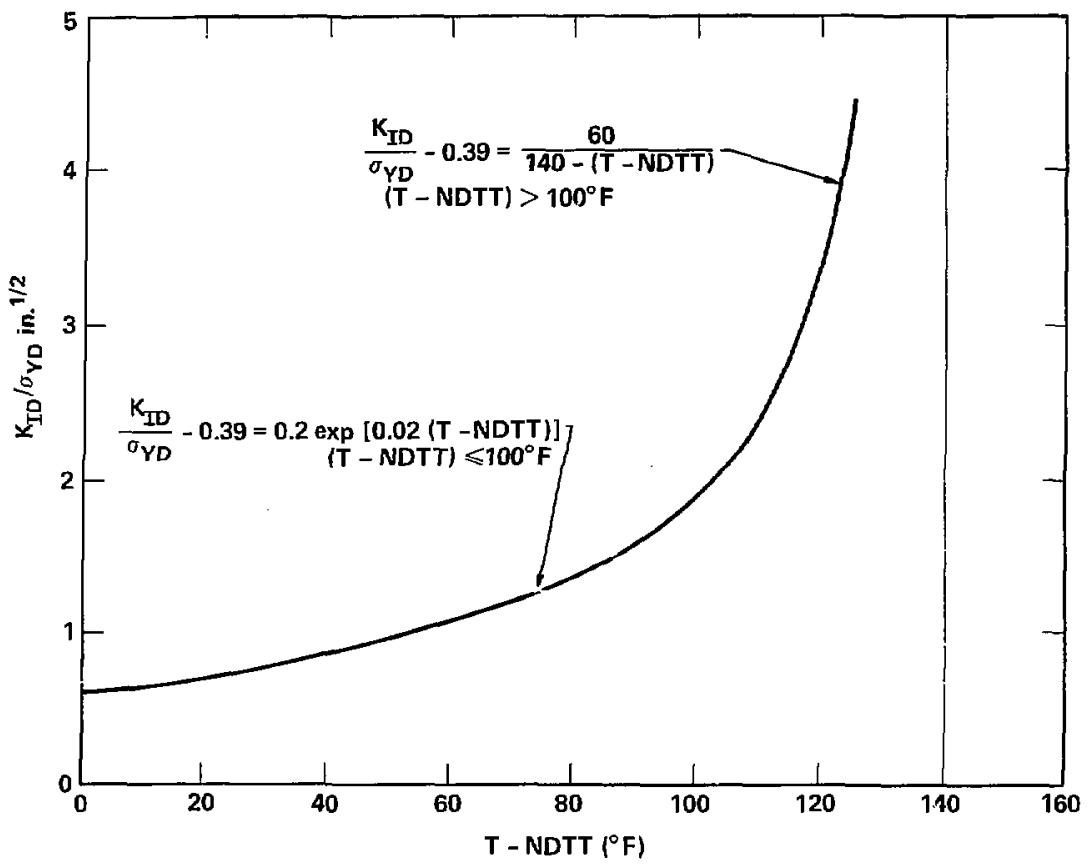

Figure 9. Projected Fracture Toughness Reference Curve. 
Thickness (in.)

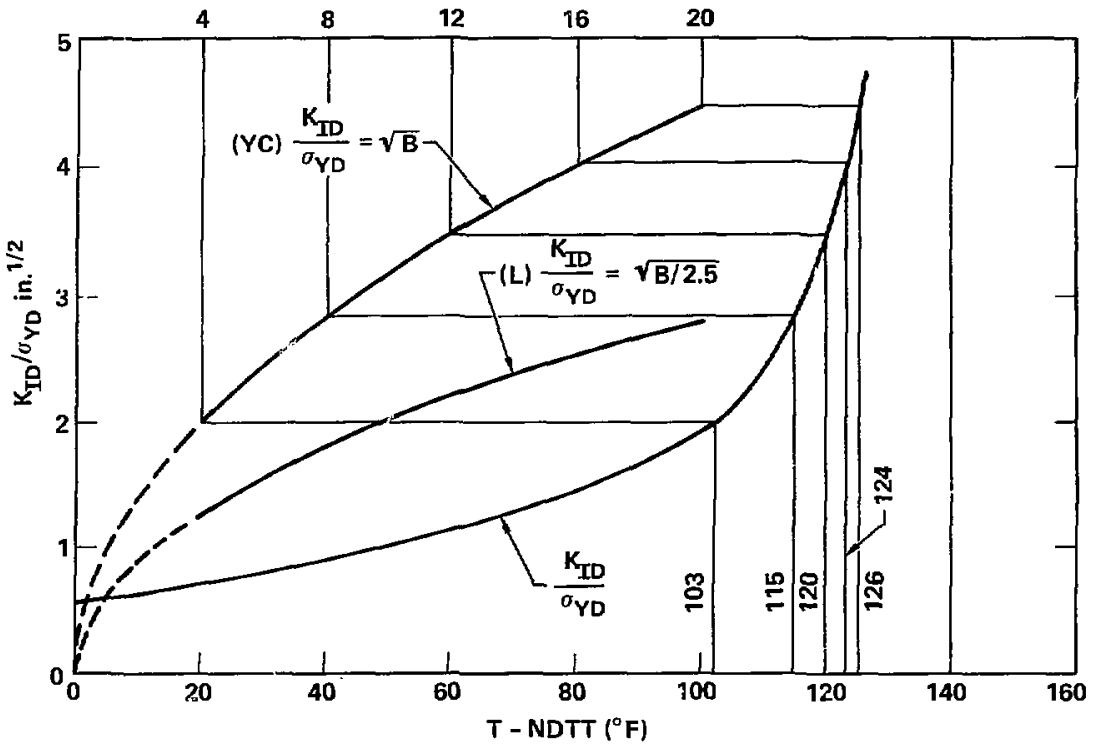

Figure 10. Method of Escablishing (YC) Coordinated for a Range of Wali Thicknesses. 


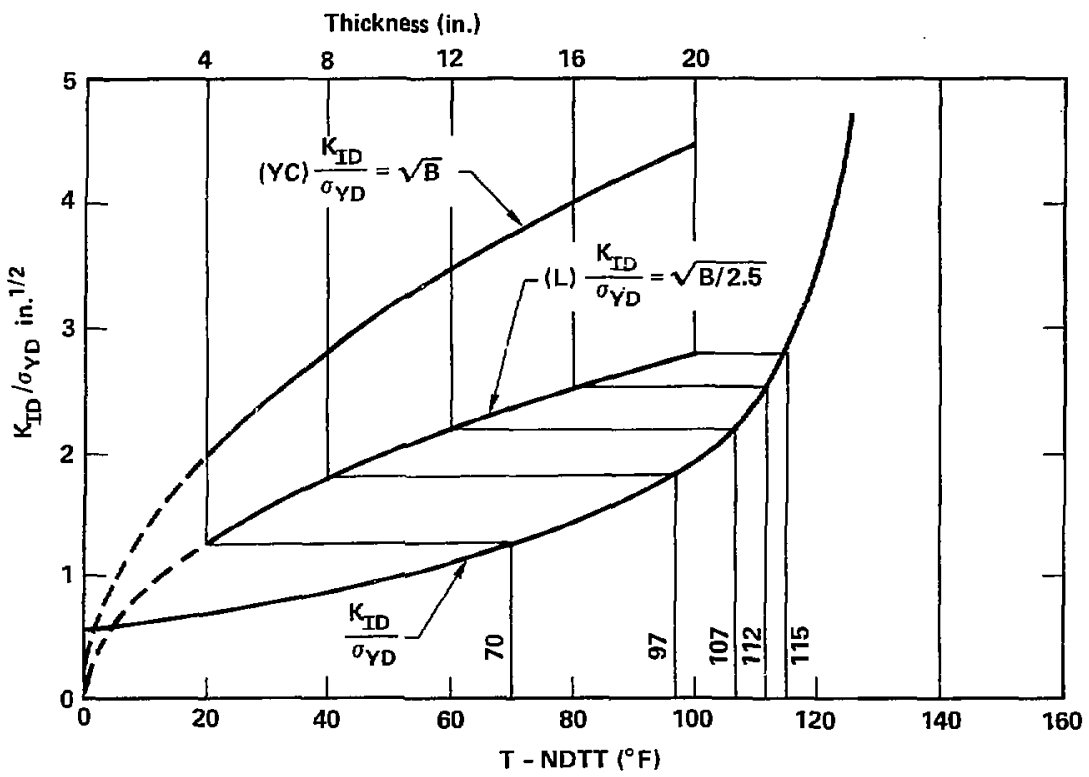

Figure 11. Method of Establishing (L) Coordinates for a Rauge of Wall Thickness. 


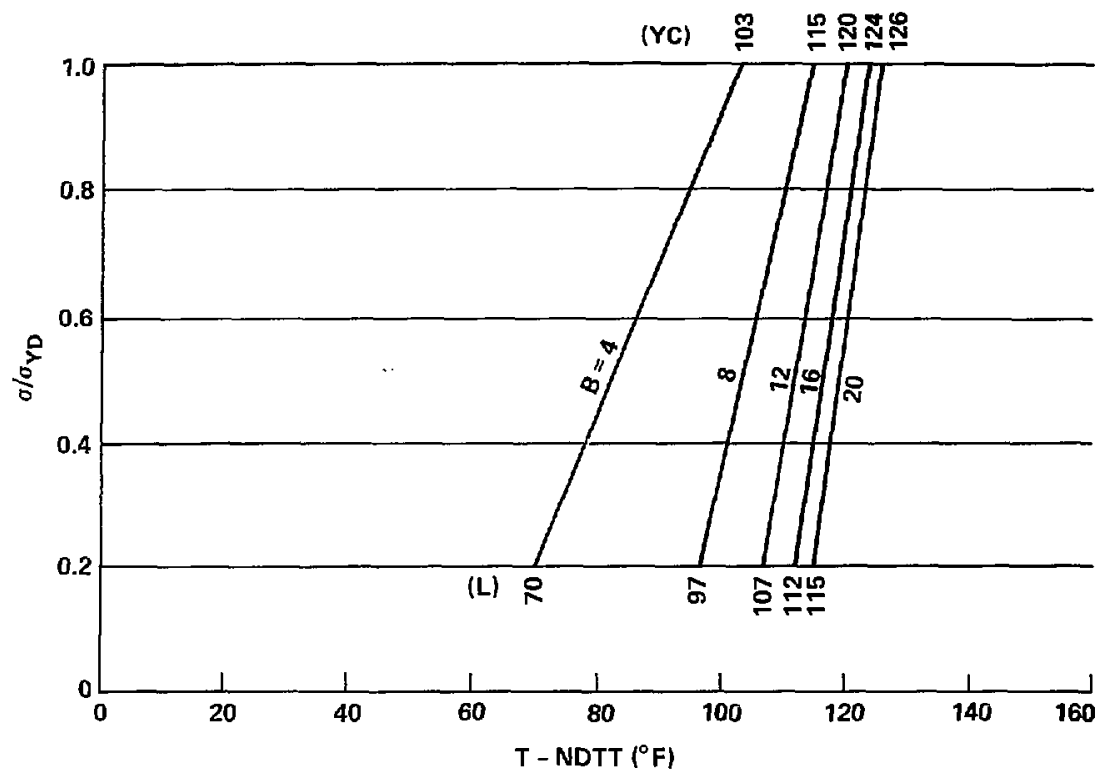

Figure 12. Fracture Arrest Boundary Curves for a Range of Wall Thicknesses.

Table 2. $\mathrm{T}_{\mathrm{NDT}}$ reguirements for: $\mathrm{LST}=-20^{\circ} \mathrm{F}$ using asymptotic $\mathrm{K}_{\mathrm{ID}} / \mathrm{\sigma}_{\mathrm{YD}}$ reference curve.

$$
\mathrm{T}_{\mathrm{NDT}}\left({ }^{\circ} \mathrm{F}\right)
$$

\begin{tabular}{cccccc}
$\begin{array}{c}\text { Thickness } \\
(\text { in. })\end{array}$ & $\frac{\sigma}{\sigma_{y}}=1.0$ & $\frac{\sigma}{\sigma_{y}}=0.8$ & $\frac{\sigma}{\sigma_{y}}=0.6$ & $\frac{\sigma}{\sigma_{y}}=0.4$ & $\frac{\sigma}{\sigma_{y}}=0.2$ \\
\hline 1 & -65 & -55 & -45 & -35 & -25 \\
\hline 8 & -123 & -115 & -107 & -98 & -90 \\
12 & -135 & -130 & -126 & -121 & -117 \\
16 & -140 & -137 & -134 & -131 & -127 \\
20 & -144 & -141 & -138 & -135 & -132 \\
\hline
\end{tabular}


fracture initiation on yield-level stresses. Prudence also dictates that a reasonable margin of safety be applied to the critical flaw size indicated by the fracture-mechanics analyses. Further conservatism may be introduced by assuming primary membrane stresses (at yield level) acting in a direction normal to the flaw so that arrest is not expected as a result of crack advance into a decreasing stress gradient. Surface flaws are assumed since they give higher stress intensity values than subsurface flaws of the same size and aspect ratio. However, the possibility exists, especially for large wall thickness, that fracture toughness values away from the surface may be smaller than those at the surface, so that the effect of subsurface flaws may have to be evaluated.

For surface flaws, the expression for stress intensity in Mode I crack loadings is

$$
K_{I}=\sigma_{m} M_{m} \sqrt{\pi} \sqrt{\frac{a}{Q}}
$$

where $\sigma_{m}$ is the membrane stress, a is the flaw depth, $M_{m}$ is a factor which reflects the influence of the ratio of flaw depth to thickness and may be obtained from Fig. 13, while $Q$ is a factor that reflects the influence of the flaw aspect ratio and may be determined from Fig. 14. Assuming dynamic yield stress levels and a critical flaw size $a_{i}$, then

$$
\frac{K_{L D}}{\sigma_{Y D}}=M_{m} \sqrt{\pi} \sqrt{\frac{a_{i}}{Q}}
$$

where $\mathrm{K}_{\mathrm{ID}}$ is the critical stress intensity of the material. $\mathrm{K}_{\mathrm{ID}} / \sigma_{\mathrm{YD}}$ ratios as a function of critical flaw depths are shown in Figs. 15, 16, and 17 for flaw aspect ratios of $1 / 2,1 / 6$ and approching zero, respectively, and for a range of wall thickness. Note, that for aspect ratios of $1 / 2$, the critical flaw depth is practically independent of the wall thickness.

Equation (5) may be used as a basis for selecting steels for shipping containers provided that inspection capability exists for revealing flaws as small as the maximum tolerable flaw. Suppose, for example, that a critical depth of 0.5 inches with aspect ratio of $1 / 6$ is chosen for a 12-in. wall thickness. From Fig. 16, the minimum toughness required is a $\mathrm{K}_{\mathrm{ID}} / \sigma_{\mathrm{YD}}$ 


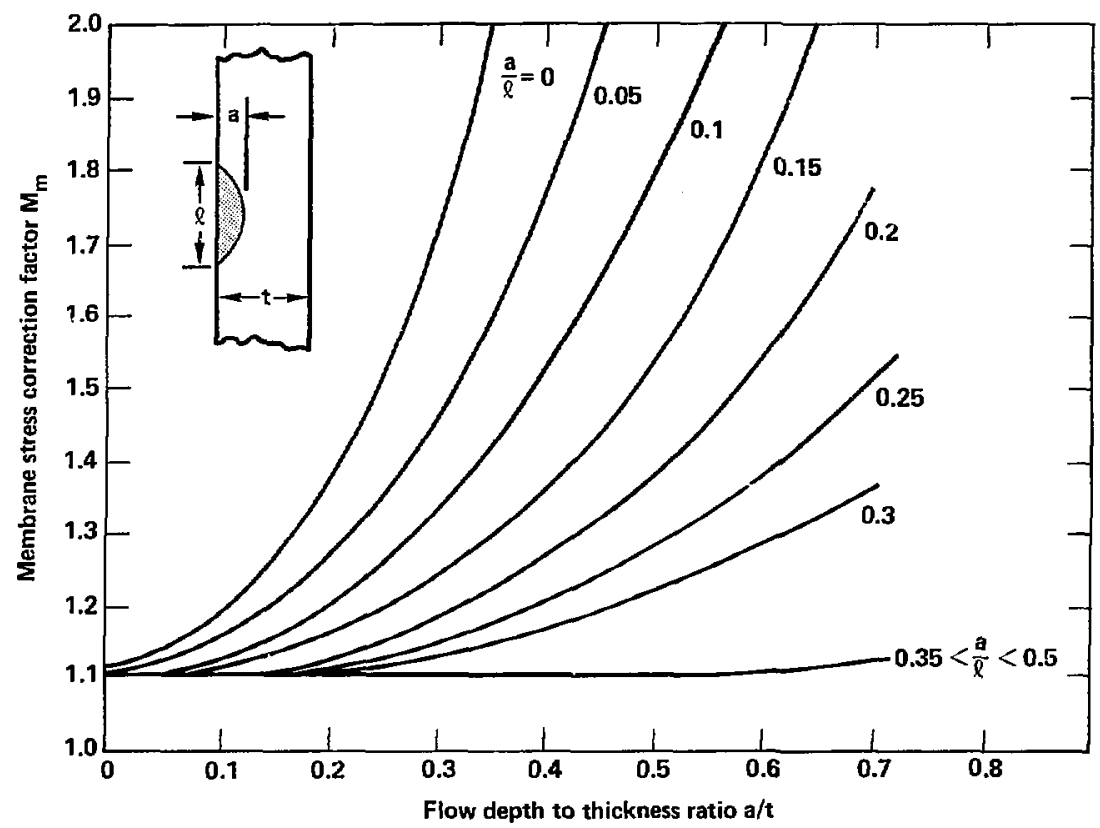

Note: $t$ is the wsll thickness; $l$ is the major axis of ellipse circumscribing the flaw.

Figure 13. Membrane Stress Correction Factor for Surface Flaws (Ref. 10). 


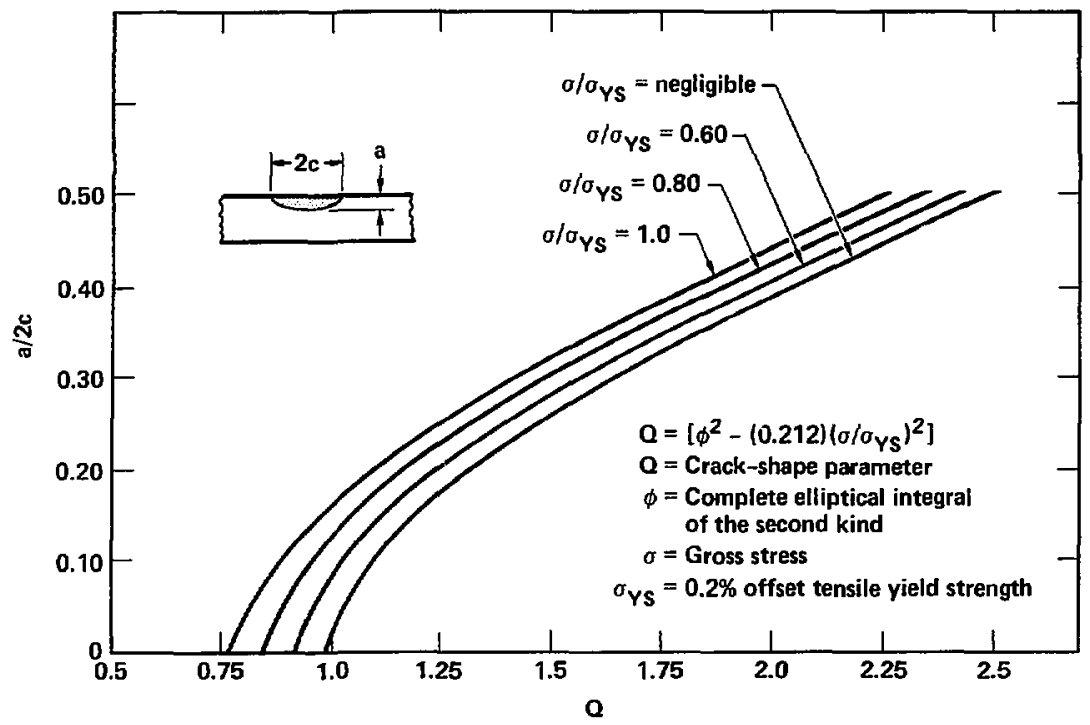

Figure 14. Crack-Shape Parameter Curves. 


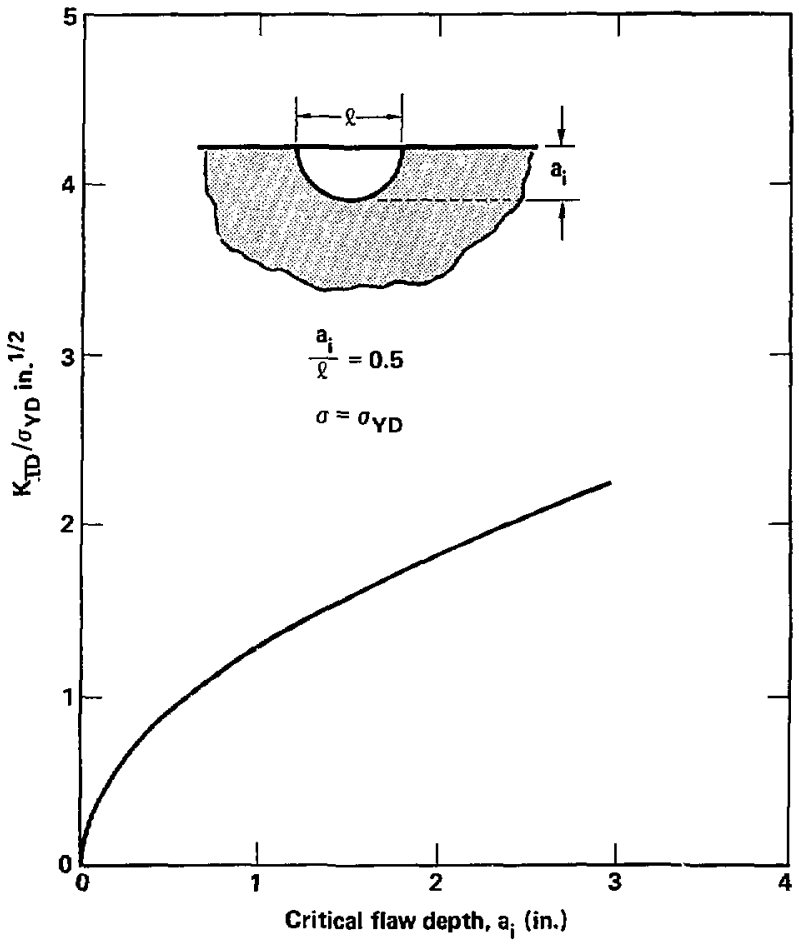

Figure 15. Fracture Toughness Level Corresponding to Critical Flaw Depth for Surface Flaw with Aspect Ratio of 0.5 for all thickness. 


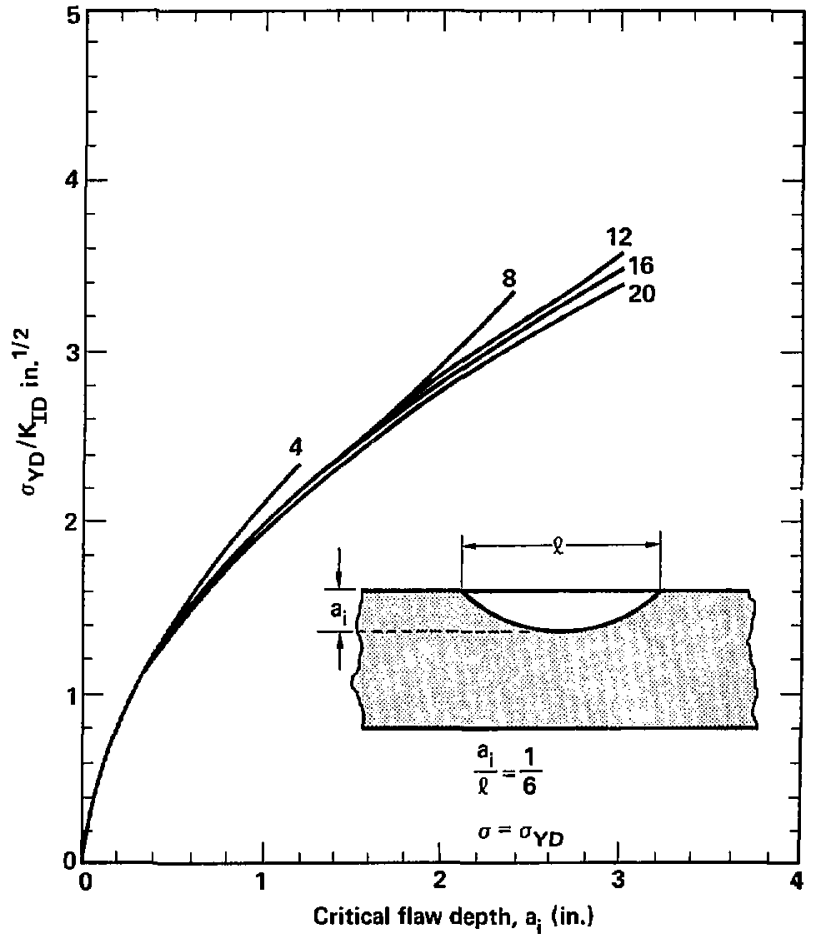

Figure 16. Fracture Taughness Level Corresponding to Critical Flaw Depth for Surface Flaw with Aspect Ratio of $1 / 6$. 


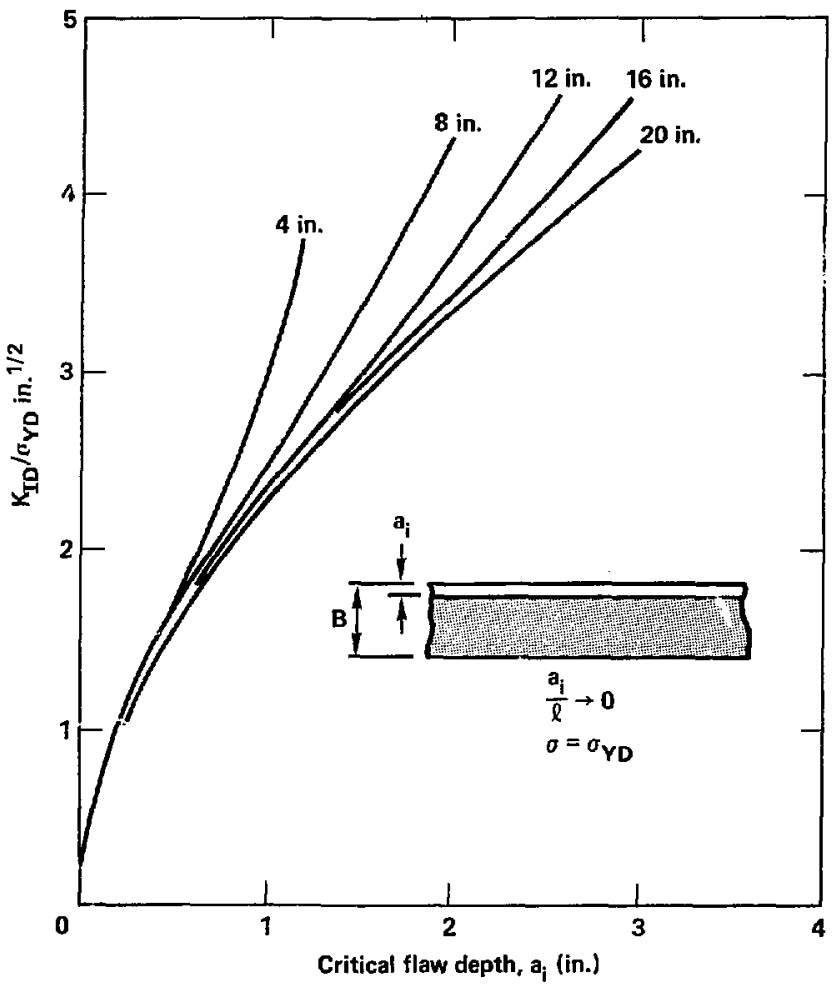

Figure 17. Fracture Toughness Level Corresponding to Critical Flaw Depth for Surface Flaw With Aspect Ratio Approaching Zero. 
ratio of 1.4. This corresponds to a T-NDTT value of about $80^{\circ} \mathrm{F}$ from Fig. 9 or a $\mathrm{T}_{\mathrm{NDT}}$ of $-100^{\circ} \mathrm{F}$ for a LST of $-20^{\circ} \mathrm{F}$. Assuming a margin of safety of 2 , based upon that recomnended in ASME Sect. XI, the actual flaw depth as revealed by inspection should not exceed 0.25 inches. The criteria for selecting a steel having a $\mathrm{T}_{\mathrm{NDT}}$ of $-100^{\circ} \mathrm{F}$ in this example hinges on the ability to resolve flaw sizes at least 0.25 in. deep. Since fractireinitiation selection criteria for materials is dependent upon inspection capability, this approach requires some rational basis for establishing minimum flaw sizes that the industry can indeed detect with a high degree of reliability. A guide to establishing these minimum flaw sizes and, incidentially, the establishment of minimum $T_{N D T}$ requirements using a fracture initiation approach is provided by the allowable flaw size criteria contained in Table IWB-3510-1 of Sect. XI of the ASME Code. This table, which is reproduced in Fig. 18 for convenience, gives the allowable planar indications for both surface and subsurface flaws in terms of the flaw-depth-to-wa11-thickness ratio and as a function of the flaw aspect ratio.

Using Eq. (5) we can now compute $K_{I D} / \sigma_{Y D}$ ratios and determine the corresponding $\mathrm{T}_{\mathrm{NDT}} \mathrm{s}$ for a range of ferritic steel forging thicknesses as shown in Table 3 for aspect ratios of $1 / 2,1 / 6$, and approaching zero, respectively. Note that since the "a" values in Table 1WB-3510-1 are flaw sizes revealed by inspection, they must be less than the critical flaw sizes. The data in Table 3 are based upon critical flaw sizes twice as large as those that can be identified by inspection in accordance with Table 1WB-3510-1. The relationship between wall thickness and $\mathrm{T}_{\text {NDT }}$ is further illust.:ated by plotting the data of Table 3 in Fig. 19. This figure reveals a significant effect of flaw aspect ratio in the allowable $\mathrm{T}_{\mathrm{NDT}}$ characteristics of the steel. For aspect ratios smaller than $1 / 6$ there appears to be little variation of $T_{\text {NDT }}$ with aspect ratio. However, between $a / 2=1 / 6$ and $a / l=$ $1 / 2$, the $\mathrm{T}_{\mathrm{NDT}}$ requirements appear to increase significantly with rlaw aspect ratio. For purposes of comparison, the relationship of $\mathrm{T}_{\mathrm{NDT}}$ to thickness for the fracture arrest criteria is shown as a dashed curve in Fig. 19.

\subsection{ACCEPTANCE CRITERION BASED ON TESTING}

Appendix B of $10 \mathrm{CFR} 71$ specifies the test conditions for qualifying a spent fuel shipping container to withstand loadings due to an accident. 
TABLE IHB-3510-1

ALLOWABLE PLANAR INDICATIONS

Material: Ferritic steels that meet the requirements

of $\mathrm{NB}-2331$ and the specified minimum yield

strength of $50 \mathrm{ksi}$ or less at $100^{\circ} \mathrm{F}$

Thickness range: $4 \mathrm{in}$, and greater

\begin{tabular}{lcc}
\hline $\begin{array}{c}\text { Aspect } \\
\text { Ratio, }\end{array}$ & $\begin{array}{c}\text { Surface } \\
\text { Indication, } \\
a / t, \%\end{array}$ & $\begin{array}{c}\text { Subsurface } \\
b-d\end{array}$ \\
\hline 0.00 & 1.8 & $2.3 \mathrm{Y}$ \\
0.05 & 2.0 & $2.4 \mathrm{Y}$ \\
0.10 & 2.2 & $2.6 \mathrm{Y}$ \\
0.15 & 2.4 & $2.9 \mathrm{Y}$ \\
0.20 & 2.7 & $3.2 \mathrm{Y}$ \\
0.25 & 3.1 & $3.7 \mathrm{Y}$ \\
0.30 & 3.5 & $4.1 \mathrm{Y}$ \\
0.35 & 3.5 & $4.6 \mathrm{Y}$ \\
0.40 & 3.5 & $5.2 \mathrm{Y}$ \\
0.45 & 3.5 & $5.8 \mathrm{Y}$ \\
0.50 & 3.5 & $6.5 \mathrm{Y}$ \\
\hline
\end{tabular}

NOTES :

(a) For intermediate flaw aspect ratios a/ $\ell$, linear interpolation is permissible.

(b) Component thickness $t$ is measured normal to the pressure retaining surface of the component. Where the section thickness varies, the average thickness over the length of the planar indication is the component thickness.

(c) The total depth of a subsurface indication is 2 a.

(d) $Y=(s / t) /(a / t)=s / a$. If $Y<0.4$, the flaw indication is classified as a surface indication. If $\mathrm{Y}>1.0$, use $\mathrm{Y}=1.0$.

Figure 18. Table from ASTM Section XI Specifying Minimum Tolerable Flaw Sizes as a Function of Section Thickness and Flaw Aspect Ratio (Ref. 10). 
Table 3. T $T_{\text {NDT }}$ reguirements based upon minimum ASME Section XI flaw sizes for brittle fracture using the fracture initiation approach.

Flaw aspect ratio, $a / \ell=0.5$

\begin{tabular}{|c|c|c|c|c|c|}
\hline $\begin{array}{c}\text { Thickness } \\
\text { B (in.) }\end{array}$ & $\begin{array}{c}a=0.035 \mathrm{~B} \\
(\text { in. })\end{array}$ & $\begin{array}{l}a_{i}=2 a \\
(\text { in. })\end{array}$ & $\frac{I^{/ \sigma_{Y D}}}{\sqrt{2 \mathrm{n}}}$ & $\begin{array}{c}\text { T-NDTT } \\
\left({ }^{\circ} \mathrm{F}\right)\end{array}$ & $\begin{array}{l}\mathrm{T}_{\text {NDT }} \\
\left({ }^{\circ} \mathrm{F}\right)\end{array}$ \\
\hline 4 & 0.14 & 0.28 & 0.69 & 20 & -40 \\
\hline 8 & 0.28 & 0.56 & 0.97 & 53 & -73 \\
\hline 12 & 0.42 & 0.84 & 1.19 & 69 & -89 \\
\hline 16 & 0.56 & 1.12 & 1.38 & 80 & -100 \\
\hline 20 & 0.70 & 1.40 & 1.54 & 87 & -107 \\
\hline
\end{tabular}

Flaw aspect ratio, $a / \ell=1 / 6$

\begin{tabular}{cccccr}
$\begin{array}{c}\text { Thickness } \\
\text { B (in.) }\end{array}$ & $\begin{array}{c}a=0.024 \mathrm{~B} \\
(\mathrm{in})\end{array}$ & $\begin{array}{c}\mathrm{a}_{\mathbf{i}}=2 \mathrm{a} \\
(\mathrm{in} .)\end{array}$ & $\begin{array}{c}\mathrm{K}_{\mathrm{ID}} / \mathrm{a}_{\mathrm{YD}} \\
\sqrt{\mathrm{in} .}\end{array}$ & $\begin{array}{c}\mathrm{T} \text {-NDTT } \\
\left({ }^{\circ} \mathrm{F}\right)\end{array}$ & $\begin{array}{c}\mathrm{T}_{\text {NDT }} \\
\left({ }^{\circ} \mathrm{F}\right)\end{array}$ \\
\hline 4 & 0.10 & 0.20 & 0.87 & 44 & -64 \\
8 & 0.19 & 0.38 & 1.20 & 70 & -90 \\
12 & 0.29 & 0.58 & 1.48 & 85 & -105 \\
16 & 0.38 & 0.76 & 1.69 & 94 & -114 \\
20 & 0.48 & 0.96 & 1.90 & 101 & -121
\end{tabular}

$$
\text { Flaw aspect ratio, } a / \ell+0
$$

\begin{tabular}{cccccr}
$\begin{array}{c}\text { Phickness } \\
\text { B (in.) }\end{array}$ & $\begin{array}{c}\mathrm{a}=0.018 \mathrm{~B} \\
\text { (in.) }\end{array}$ & $\begin{array}{c}\mathrm{a}_{\mathrm{i}}=2 \mathrm{a} \\
\text { (in.) }\end{array}$ & $\begin{array}{c}\mathrm{K}_{\text {ID }} / \sigma_{\mathrm{YD}} \\
\sqrt{\mathrm{in} .}\end{array}$ & $\begin{array}{c}\mathrm{T} \text {-NDTT } \\
\left({ }^{\circ} \mathrm{F}\right)\end{array}$ & $\begin{array}{c}\mathrm{T}_{\text {NDT }} \\
\left({ }^{\circ} \mathrm{F}\right)\end{array}$ \\
\hline 4 & 0.072 & 0.144 & 0.84 & 41 & -61 \\
8 & 0.144 & 0.288 & 1.19 & 69 & -89 \\
12 & 0.216 & 0.432 & 1.46 & 84 & -104 \\
20 & 0.288 & 0.576 & 1.66 & 93 & -113 \\
\hline
\end{tabular}




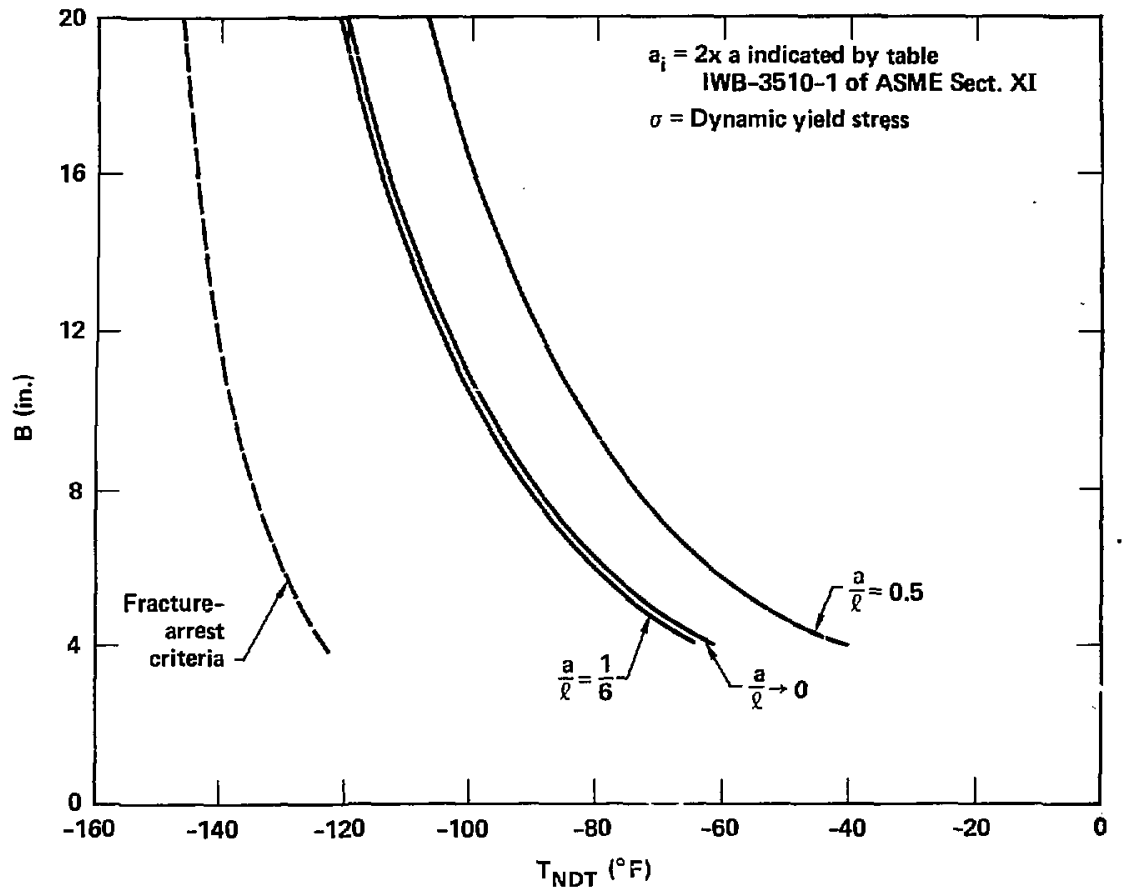

Figure 19. NIL Ductility Transition Temperature Requirements far Thick Wall Forgings Based Upon Fracture Initiation Criterion. 
Specification B1 clearly requires that the shipping container drop through a distance of 30 feet and strike an essentially unyielding surface in a position for which maximum damage is expected. For a container material having homogeneous mechanical properties, this simply amounts to finding the orientation that will result in attainment of the maximum level of stress or strain. However, the properties of real material vary not only from one shipping container to another but also throughout a particular container. It is prudent, then, to verify that the mechanical property values coincident with the location of maximum stress are not significantly better than the minimum allowab:e if the test is to reflect future behavior of the container under accident conditions. This is especially true for a material that is considered to be flaw sensitive. While the location of the maximum stress may be well defined for a given container configuration, the location of a potentially critical flaw can vary randomly throughout the container. Furthermore, the dynamic critical stress intensity for the same material is usually claracterized by a large variation in its value so that a valid drop test must assure the coincidence of the maximum anticipated stress, the largest flaw size that might pass inspection, and the lowest values of dynamic initial stress intensity. Since it is unlikely that the test container will satisfy this requirement, it will be necessary to introduce a flaw at the location of maximum anticipated stress and, if no failure results, analyze the material to ascertain the actual value for dynamic critical stress intensity in the vicinity of the flaw. If the toughness is above the design value established for the dynamic critical stress intensity, then the maximum flaw size that can be tolerated must be decreased in the proportion

$$
\frac{a_{\text {maximum allowable }}}{a_{\text {Test }}}=\left(\frac{K_{I D} \text { Design }}{k_{I D} \text { Test }}\right)^{2}
$$

The size and aspect ratio of the flaw that is originally introduced may be optional recognizing, of course, that the selected flaw geometry will establish the degree of rigor of the inspection requirements. However, the flaw configuration must be crack-like and placed normal to the direction of the stress. It is apparent too that the dynamic fracture toughness properties of the material must be established to an extent that allows the specification of a lower bound with a high probability of being exceeded. 


\section{SENSITIVTTY OF FER RITIC STEEL SHIPPING CONTAINERS TO FABRICATION PROCESSES}

The brittle fracture sensitivity of shipping containers made from ferritic steel forgings to various processes is reflected by the effect of these processes on the fracture toughness of the material, the flaws that may be introduced, and the level of residual stresses. The processes which have : major effect upon the resistance to fracture are: (1) the fabrication of the forging billet, (2) the furging process, (3) heat treatment, and (4) welding the forged segments together to form the shipping container.

\section{1 FABRICATION OF THE FORGING BILLET}

The material used for forging is usually hot-rolled from ingots melted in open-hearth, electric, or vacuum furnaces. Consequently the billets have usually undergone considerable reduction before the forging operations. This reduces to a considerable extent the ingot imperfections such as pipes, seams, and segregation. Subsequent forging results in a further reduction of these defects, but poor forging practice may introduce other types of imperfections. The presence of nonmetallic inclusions such as sulfide particles are unavoidable constituents of the original ingot. Brittle fracture behavior is sensitive to their presence to the extent that they serve as crack-growth nuclei under cyclic loading conditions. 7

\subsection{THE FORGING PROCESS}

While the hardness and strength of steel is controlled, primarily, by composition and heat treatment, the forging process has a torked effect upon ductility and fracture toughness. Forging breaks up segregation, heals porosity, and generally provides a more homogeneous microstructure. 8 It produces a fibrous grain structure that improves the toughness properties parallel to the direction of grain flaw. Furthermore, it reduces the as-cast grain size which also results in a significant increase in toughness. While forging enhances the fracture-toughness properties of the steel, it may introduce flaws that lower its resistance to dynamic loads depending on their size, shape, location, orientation, and sh.urpness. 
The two major types of forging defect are forgings laps and forging bursts. 9 The forging lap is a defect that forms whenever metal folds over itself during forging. It is usually near the surface and can be easily detected. The lap is characterized by a thin platelike formation on the surface where the metal has folded and can be distinguished from other types of defects by the presence of oxides, lubricant, or other contaminants enveloped during forging. Forging bursts can either be open to the surface or occur below the surface and are usually caused by forging at too low a temperature. The occurrence of surface bursts or hot tears are also influenced by the presence of segregation, seams, or brittle second phases. The mechanisus that cause internal or center bursts are similar to those that cause surface bursts. There is, in addition, the possibility of center bursts occurring when large, rapid reductions increase the metal temperature to near its melting point.

Another imperfection that may occur in forgings is the thermal crack which can occur either during cooling or heating. Internal cracks or flakes occur during cooling as a result of excessive accumulation of hydrogen at grain boundaries, lattice imperfections, or other microstructural discontinuities. They frequently occur in large sections when forgings cool at normal air-cooling rates. Cooling cracks of this type can be avoided by cooling forgings slowly either in insulating material or in a furnace. Internal cracks can also form when the forging is heated too rapidly causing the surface to expand more rapidly than the cooler metal in the center where large tensile stresses can develop.

\subsection{HEAT TREATMENT}

Ferritic steel forgings are generally heat-treated to develop the required mechanical properties and to reduce the residual stresses developed by the forging process. Forg:irs are heated to a temperature that produces an austenitic structure and then are quenched in a suitable liquid medium. This is followed by tempering at a subcritical temperature for a period of time that depends upon the thickness of the section. Large thick forgings are more difficult to quench rapidly than plate products because of the difference in handling facilities that are availabie for the two product forms. As a 
consequence, there may be a toughness gradient throughout the section, but it is important to assure that at least the material to a depth of a few inches develops optimum toughness properties. This requirement is dictated by the fact that surface flaws are the most hazardous, and their allowable size to prevent fracture initiation depends upon the level of toughness in the immediate vicinity of the flaw.

\subsection{WELDING}

If the shipping container is fabricated from forged segments such as rings or closures, then the parts need to be joined together by welding. The welded joint constitutes a location of potential weakness since the welding process produces a change in metallurgical structure in the area of the weld and also results in the possible introduction of defects such as porosity, slag inclusions, and shrinkage cracks. In addition, the welding process may result in high levels of residual stress.

A gradient in composition and microstructure from the weld through the heat-affected zone to the base metal is unavoidable, but its deleterious effects can be minimized by selection of the proper weld metal, flux combination, heat input, and weld atmosphere. The toughness in the area of the veld must be sufficient to preclude brittle fracture initiation for the maximum flaw size tolerated in this zone. Consequently, material evaluations of the weld, the heat, and the affected zone need to be made to determine their fracture toughness properties.

The occurrence of porosity or slag inclusions in the weld are indicative of faulty welding technique. While they do not significantly affect the strength of the joint in a ductile failure mode, they can reduce the resistance to brittle fracture. However, small amounts of porosity, while undesirable, are better left alone than repaired, since the repair process itself may introduce cracks that are less readily detectable.

The residual stresses can be reduced by annealing, but the high leval of toughness of some base materials can be reduced by stress-relief heat treatment. This is particularly true of $\mathrm{Ni}-\mathrm{Cr}-\mathrm{Mo}$ steels which are sensitive to temper embrittlement. In these cases, it would be best to use the container in the as-welded condition. This is one of the major reasons for 
suggesting that yield-level stresses be used as a design criteria for the prevention of britcle fracture. Where lower stresses are specified, the residual stress level must be reduced, but it must also be shown that the stress-relieving heat treatment did not reduce the toughness levels.of the material below its expected value. 


\section{REFERENCES}

1. ASME Boiler and Pressure Vessel Code Sect. XI "Rules for Inservice Inspection or Nuclear Power Plant Components," New York American Society of Mechanical Engineers (1980).

2. Cumings, R. C., "Discontinuity Detection Using Nondestructive Testing," Materials Evaluation, (USA) 35 (7) (July, 1977) p. 32-33.

3. Holman, W. R. and Langland, R. T., "Recommendations for Protecting Against Failure by Brittle Fracture in Ferritic steel Shipping Containers up to Four Inches Thick," Lawrence Livermore National Laboratory, Livermore, CA, NUREG/CR-1815 (June 1981).

4. Pellini, W. S., "Criteria for Fracture Control Plans," Washington, D.C., Naval Research Laboratory, Report 7406 (May, 1972).

5. Pellini, W. S., "Manual of Engineering Procedures for Fracture Safe Design," Chicago, Association of American Railroads, R-451 (November 1980).

6. Pellini, W. S. and Loss, F. J., "Integration of Metallurgical and Fracture Mechanics Concepts of Transition Teuperature Factors Relating to Fracture-Safe Design for Structural Steels," New York, Welding Rescarch Council, Bulletin 141 (June 1969).

7. Rolfe, S. T. and Barsom, J. M., Fracture and Fatigue Control in Structures (Prentice-Hall, Englewood Cliffs, NJ).

8. Sabroff, A. M., Boulger, F. W., Henning, H. J., "Forging Materials and Practices," Reinhold Book Corp., New York (1968) p. 7. 
9. Timo, D. P., Gurran, R. M. Placer, R. S., "The Development and Evaluation of Improved Rotor Forgings for Modern Large Steam Turbines," Workshop Proceedings, ROTOR Forgings for Turbines and Generators, Palo Alto, CA, Electric Power Research Institute EPRI WS-79-235 (Sept. 1981).

10. Wesse1, E. T. and Mager, T. R., "Fracture Mechanics Technology as Applied to Thick-Walled Nuclear Pressure Vessels," Inst. Mech. Engrs. CY/7l.

BED/mc 
Brittle fracture

Containment vessel

Ferritic steel

Fracture-arrest conditions

Fracture-initiation conditions

Nominal stress
Crack propagation at nominal stresses below the yield stress of the material.

The receptacle on which principal reliance is placed to retain the radioactive material during transport.

Stee 1 with a microstructure that is predominately ferritic ("ferrite: a solid solution of one or more elements in body-centered cubic iron." Metals Handbook, 8th ed.)

Combinations of nominal stress and toughness that will stop a propagating crack.

Combinations of nominal stress, toughness and crack size that result in crack extension.

The maximum principal tensile stress at a point in the absence of a flaw-considering primary stresses as defined in Regulatory Guide 7.6 and secondary membrane stresses that exist over a substantial portion of the structure.

A narrow temperature range in which the toughness increases rapidly with temperature from a lower to an upper shelf level. 
The stress ratio $\mathrm{o} / \mathrm{o}_{\mathrm{y}}$ that determines the coordinate for $\mathrm{L}$ is related to the size of through-crack that is critical at that stress level. For plane strain conditions linear elastic fracture mechanics calculations are applicab1e. For a through-crack

$$
K_{I}=\sigma \sqrt{\pi a}
$$

where $K_{I}$ is the stress intensity normal to the plane of the crack, $\sigma$ is the stress and $a$ is one half the crack length. The critical stress for a given flaw size can be expressed by

$$
\sigma_{i}=\frac{K_{I D}}{\sqrt{\pi a}}
$$

where $K_{I D}$ is the dynamic critical stress intensity. Dividing both sides of Eq. (A-2) by the dynamic yield strength $\sigma_{Y D}$ gives

$$
\frac{\sigma_{i}}{\sigma_{Y D}}=\frac{1}{\sqrt{\pi a}} \frac{K_{I D}}{\sigma_{Y D}} .
$$

Recalling that for plane strain conditions

$$
\frac{K_{I D}}{\sigma_{Y D}}=\sqrt{\frac{B}{2.5}},
$$

and substituting this expression in Eq. (A-3) yields

$$
\frac{\sigma_{i}}{\sigma_{Y D}}=\sqrt{\frac{B}{2.5 \pi a}} .
$$


If we now let the ratio of the crack length to the thickness be expressed by

$$
n=\frac{2 a}{B}
$$

then

$$
\frac{\sigma_{i}}{\sigma_{Y D}}=\frac{0.505}{\sqrt{n}} .
$$

Note that at a ratio of crack length to thickness of about 6.38 , the critical stress level is $0.2 \sigma_{\mathrm{YD}^{*}}$ In other words, if the design stress is $0.2 \sigma_{\mathrm{YN}}$ ' the tatal crack length, $2 \mathrm{a}$, must be about 6.38 times the wall thickness before this design stress $\left(0.2 \mathrm{\sigma}_{\mathrm{YD}}\right)$ will result in brittle fracture at the $L$ temperature. 
APPENDIX B. THICK SECTION $\mathrm{K}_{\text {ID }} / \sigma_{\mathrm{YD}}$ DESIGN REFERENGE CURVE

Using the concept of a limiting transition temperature range as defined by DT Lests (Ref. 5),

$$
\begin{aligned}
\text { FTE* } & =\mathrm{NDT}+60^{\circ} \mathrm{F} \text { for thin section, } \\
\text { and } \mathrm{FTE} & =\mathrm{NDT}+140^{\circ} \mathrm{F} \text { for thick sections. }
\end{aligned}
$$

An inverse relation asymptotic to NDTT $+140^{\circ} \mathrm{F}$ can be expressed by

$$
\frac{K_{I D}}{\sigma_{Y D}}=\frac{x}{140-(\mathrm{T}-\mathrm{NDTT})}+0.39
$$

at $\left((\mathrm{T}-\mathrm{NDTT})=100^{\circ} \mathrm{F}\right)$ let $\frac{\mathrm{K}_{\overline{I D}}}{{ }_{\mathrm{Y}}}=1.89($ Pellini);

then $\frac{X}{40}=0.39-1.89$,

and $X=60$.

Therefore $\frac{K_{I D}}{\sigma_{Y D}}=\frac{60}{140-(\mathrm{T}-\mathrm{NDTT})}+0.39 ;(\mathrm{T}-\mathrm{NDTT})>100^{\circ} \mathrm{F}$.

\begin{tabular}{rlcc}
\hline T-NDTT & $\begin{array}{c}K_{I D} / \sigma_{Y D} \\
\text { (Inverse) }\end{array}$ & $\begin{array}{c}K_{I D} / \sigma_{Y D} \\
(\text { Exponential) }\end{array}$ & $\begin{array}{l}K_{I D} / \sigma_{Y D} \\
\text { (Proposed) }\end{array}$ \\
\hline 0 & 0.32 & 0.60 & 0.60 \\
20 & 0.89 & 0.70 & 0.70 \\
40 & 0.99 & 0.86 & 0.86 \\
60 & 1.14 & 1.11 & 1.11 \\
80 & 1.39 & 1.46 & 1.46 \\
100 & 1.89 & 1.89 & 1.89 \\
110 & 2.39 & 2.14 & 2.39 \\
120 & 3.39 & 2.74 & 3.39 \\
125 & 4.39 & & 4.39 \\
130 & 6.39 & & 6.39 \\
140 & & & \\
\hline
\end{tabular}

*Fracture Transition Elastic. 